\title{
2-(4-Phenyl-5-pyridin-2-yl-4H-1,2,4-triazol-3- yl)cyclohexanecarboxylic Acid and Its DMSO Solvate: Synthesis, Crystal Structure and Biological Activity
}

\author{
Liliana Mazur • Anna E. Koziol • Bożena Modzelewska-Banachiewicz • \\ Marzena Ucherek • Michał Zimecki · Jolanta Artym
}

Received: 6 December 2010/ Accepted: 31 January 2011/Published online: 15 February 2011

(c) The Author(s) 2011. This article is published with open access at Springerlink.com

\begin{abstract}
A new 1,2,4-triazole derivative, 2-(4-phenyl-5pyridin-2-yl-4H-1,2,4-triazol-3-yl)cyclohexanecarboxylic acid, $\mathrm{C}_{20} \mathrm{H}_{20} \mathrm{~N}_{4} \mathrm{O}_{2}$ (I), and its dimethyl sulfoxide solvate 1:1 (II) have been synthesized and their crystal structure was established. Compound (I) was screened for its antiproliferative and antiinflammatory activity. Structural analysis indicated the substantial difference between two symmetry independent molecules in (I) and this in (II), it manifests in the relative orientation of pyridine/phenyl and triazole rings, as well as in the orientation of carboxyl group with respect to cyclohexane ring. The molecules $\mathrm{A}$ and $\mathrm{B}$ in the crystal (I) form two hydrogen-bonded chains through $\mathrm{O}-\mathrm{H}_{\text {carboxyl }}$ and $\mathrm{N}_{\text {triazole }}$ atoms, giving separate catemers of symmetry independent molecules. The catemer of (IA) running along the $2_{1}$ axis is homochiral, while the catemer (IB) is racemic-formed about the $c$ glide plane. In the crystalline solvate (II) complexation of (I) with DMSO induced enantiomeric self-resolution. Obtained crystals are racemic twins, in which each part is built of one enantiomer of (I) having the relative configuration $11 S, 12 R$ or $11 R, 12 S$. A pair of host-guest molecules is linked by the $\mathrm{O}-\mathrm{H}_{\text {carboxyl }} \cdots \mathrm{O}_{\text {DMSO }}$ hydrogen bond.
\end{abstract}

L. Mazur $(\bowtie) \cdot$ A. E. Koziol

Department of Crystallography, Faculty of Chemistry, Maria Curie-Sklodowska University, 20-031 Lublin, Poland

e-mail: 1mazur2@op.pl

B. Modzelewska-Banachiewicz $\cdot$ M. Ucherek

Department of Organic Chemistry, Faculty of Pharmacy,

Nicolaus Copernicus University, 85-067 Bydgoszcz, Poland

M. Zimecki · J. Artym

Institute of Immunology and Experimental Therapy, Polish

Academy of Sciences, 53-114 Wroclaw, Poland
Keywords Crystal structure $\cdot$ 1,2,4-triazole .

Racemate · DMSO solvate

\section{Introduction}

The growing interest in synthesis and structures of 1,2,4triazole and its derivatives results from their applications in the synthesis of other heterocyclic compounds or as ligands in coordination chemistry [1-3]. Triazole derivatives have a wide range of biological applications, which include notably antitumorial, antifungal, antimicrobial, antiviral, antidepressant or herbicidal activities [4-7].

In order to obtain more detailed information on the molecular conformation and patterns of hydrogen bonds of the title compound in the solid state, which may be of value in a structure-activity analysis, an X-ray analysis of 2-(4phenyl-5-pyridin-2-yl-4H-1,2,4-triazol-3-yl)cyclohexanecarboxylic acid (I) and its 1:1 DMSO solvate (II) has been undertaken. So far, no crystal structure of 4H-1,2,4-triazole derivative having cyclohexanecarboxylic acid as a substituent has been described in the literature (CSD, Ver. 5.32) [8].

\section{Experimental}

Instrumentation

All reagents and chemicals were purchased from commercial sources and used without further purification. IR spectrum was recorded on a FT-IR Perkin Elmer 1725X spectrophotometer ( $\mathrm{KBr}$ pellet, 4,000-400 $\mathrm{cm}^{-1}$ ). ${ }^{1} \mathrm{H}$ NMR spectrum was recorded at room temperature on Bruker Avance $\left(300 \mathrm{MHz}\right.$ ) apparatus using $\mathrm{DMSO}-\mathrm{d}_{6}$ as a 
solvent and TMS as an internal standard. The apparent resonance multiplicity is described as: $\mathrm{s}=$ singlet and $\mathrm{m}=$ multiplet. Elemental analysis was carried out with a CHN Perkin-Elmer 2400 analyzer. Melting point was measured on a Mel TEMP 1002D apparatus and is given uncorrected.

Single-crystal X-ray data were collected at room temperature on a four-circle Kuma KM4 diffractometer using graphite monochromated $\mathrm{Cu} \mathrm{K} \alpha$ radiation $(\lambda=1.54178 \AA$ ) and $\omega / 2 \theta$ scan mode [9]. Crystallographic details as well as parameters of data collection and refinement are summarized in Table 1. The structures were solved by direct methods using the SHELXS97 program and refined by the full-matrix least-squares on $F^{2}$ using SHELXL97 [10]. In the crystal net of (II) the DMSO molecule is disordered between two positions with the site occupancy factors (sof's) of 0.815 (6):0.185 (6). All non-H atoms in (I) and (II) were refined with anisotropic displacement parameters. All $\mathrm{H}$ atoms were positioned geometrically and constrained with $\mathrm{O}-\mathrm{H}$ bond distances of $0.82 \AA$ and $\mathrm{C}-\mathrm{H}$ distances being in the range of $0.93-0.98 \AA$; a riding model was used during the refinement process. The displacement parameters of the $\mathrm{H}$ atoms were $U_{\text {iso }}(\mathrm{H})=1.2 U_{\mathrm{eq}}(\mathrm{C} / \mathrm{O})$.
In the absence of significant anomalous scattering effect it was impossible to establish unambiguously the absolute crystal structure (I). Crystals of (II) were twinned and the DMSO molecules in their structure were disordered. Thus, determination of the relative configuration only is possible [11].

\section{Synthesis}

$N$-Phenylpicolinehydrazonamide $(10 \mathrm{mmol})$ and cis-1,2cyclohexanedicarboxylic anhydride $(10 \mathrm{mmol})$ were dissolved in anhydrous diethyl ether. The reaction was carried out in ambient temperature for 14 days. The resulting precipitate was collected by filtration, washed with diethyl ether to remove the unreacted anhydride, and heated in chloroform under reflux for $5 \mathrm{~min}$. The insoluble residue was dissolved in $2 \%$ sodium hydroxide, and the resulting solution was heated under reflux for $2 \mathrm{~h}$. The solution was cooled and acidified with hydrochloric acid solution. The product (I) was crystallized from ethanol. Yield: $45 \%$. M.p.: 224-226 ${ }^{\circ}$ C. Anal. Calcd. for $\mathrm{C}_{20} \mathrm{H}_{20} \mathrm{~N}_{4} \mathrm{O}_{2}$ : C, 68.55; H, 6.33; N, 15.99\%. Found: C, 68.76; H, 6.09; N, 15.59\%. IR (KBr, cm $\left.{ }^{-1}\right)$ : $1700(\mathrm{C}=\mathrm{O}), 2855\left(\mathrm{H}_{\text {aliph }}\right), 2936\left(\mathrm{H}_{\text {arom }}\right)$.

Table 1 Crystal data and structure refinement details for (I) and (II)

\begin{tabular}{|c|c|c|}
\hline & (I) & (II) \\
\hline Formula & $\mathrm{C}_{20} \mathrm{H}_{20} \mathrm{~N}_{4} \mathrm{O}_{2}$ & $\mathrm{C}_{20} \mathrm{H}_{20} \mathrm{~N}_{4} \mathrm{O}_{2} \mathrm{C}_{2} \mathrm{H}_{6} \mathrm{OS}$ \\
\hline Formula weight $\left(\mathrm{g} \mathrm{mol}^{-1}\right)$ & 348.4 & 426.54 \\
\hline Crystal system & Orthorhombic & Orthorhombic \\
\hline Space group & $\mathrm{Pca}_{1}$ & $P 2_{1} 2_{1} 2_{1}$ \\
\hline$a(\AA)$ & $28.330(6)$ & $9.626(2)$ \\
\hline$b(\AA)$ & $10.548(2)$ & $9.955(2)$ \\
\hline$c(\AA)$ & $12.130(2)$ & $23.230(5)$ \\
\hline$V\left(\AA^{3}\right)$ & $3624.8(12)$ & $2226.1(8)$ \\
\hline$Z$ & 8 & 4 \\
\hline Calculated density $\left(\mathrm{g} \mathrm{cm}^{-3}\right)$ & 1.277 & 1.273 \\
\hline Absorption coefficient $\left(\mathrm{mm}^{-1}\right)$ & 0.687 & 1.540 \\
\hline$F(000)$ & 1472 & 904 \\
\hline Crystal size (mm) & $0.36 \times 0.19 \times 0.09$ & $0.32 \times 0.29 \times 0.25$ \\
\hline Crystal color and form & Colorless plate & Colorless prism \\
\hline$\theta$ Range $\left({ }^{\circ}\right)$ & $3.12-80.44$ & $3.81-80.26$ \\
\hline Indexes ranges & $0 \leq h \leq 36 ;-13 \leq k \leq 13 ; 0 \leq l \leq 15$ & $-12 \leq h \leq 12 ; 0 \leq k \leq 12 ; 0 \leq l \leq 29$ \\
\hline Reflections collected/unique & $\begin{array}{l}8043 / 4165 \\
\left(R_{\mathrm{int}}=0.1116\right)\end{array}$ & $\begin{array}{l}5159 / 4811 \\
\left(R_{\mathrm{int}}=0.0844\right)\end{array}$ \\
\hline Data/restrains/parameters & $4165 / 1 / 469$ & $4811 / 0 / 283$ \\
\hline Goodness-of-fit on $F^{2}$ & 0.948 & 0.977 \\
\hline Final $R$ indices $(I>2 \sigma(I))$ & $\begin{array}{l}R_{1}=0.0418 \\
w R_{2}=0.0708\end{array}$ & $\begin{array}{l}R_{1}=0.0579 \\
w R_{2}=0.1528\end{array}$ \\
\hline$R$ indices (all data) & $\begin{array}{l}R_{1}=0.1667 \\
w R_{2}=0.0945\end{array}$ & $\begin{array}{l}R_{1}=0.1616 \\
w R_{2}=0.1987\end{array}$ \\
\hline Largest diff. peak and hole $\left(\mathrm{e} \AA^{-3}\right)$ & $0.18 /-0.23$ & $0.26 /-0.24$ \\
\hline
\end{tabular}


${ }^{1} \mathrm{H}$ NMR (300 MHz, DMSO-d $\left.6, \mathrm{ppm}\right), \delta: 12.1(1 \mathrm{H}, \mathrm{s}$, $\mathrm{COOH})$; 7.3-8.3 (9H, m, arom); 3.2-1.0 (10H, m, aliph). Crystals of compound (I), suitable for X-ray analysis, were obtained by recrystallization from methanol solution at room temperature. Single crystals of its DMSO solvate (II) were obtained from DMSO solution by slow evaporation of solvent.

\section{Biological Screening}

\section{Determination of Cell Toxicity}

Human peripheral blood mononuclear cells (PBMC) $\left(2 \times 10^{5} / 0.2 \mathrm{~mL} /\right.$ well in 96 -well plates $)$ were suspended in a culture medium, referred later to as the culture medium, consisting of: RMPI 1640, 10\% fetal calf serum, L-glutamine, sodium pyruvate, 2-mercaptoethanol and antibiotics (streptomycin and penicillin). The studied compound (I) was initially dissolved in DMSO and subsequently in the culture medium and added to the cultures at concentrations of $1-100 \mu \mathrm{g} / \mathrm{mL}$. As a control, appropriate dilutions of DMSO in the culture medium were used. Cell survival was determined by MTT colorimetric method [12] using MTT (3-(4,5-dimethylthiazol-2-yl)-2,5-diphenyl tetrazolium bromide) (Sigma). The mean optical density (OD) value at $550 / 630 \mathrm{~nm}$ from quadruplicate wells \pm standard error (SE) was analysed.

\section{Proliferation of Human Peripheral Blood Mononuclear Cells to Phytohemagglutinin A (PHA)}

Venous blood was taken into heparinized syringes and diluted two-fold with phosphate buffered saline (PBS). Blood was applied onto Lymphoprep ${ }^{\circledR}$ (Polfa, Kutno, Poland) and centrifuged for $25 \mathrm{~min}$ at $800 \times g$. Cells from the interphase were washed 3 times with PBS and re-suspended at a density of $2 \times 10 \% / \mathrm{mL}$ in the culture medium. The cells were placed then in 96-well, flat-bottom culture plates (Nunc) $\left(2 \times 10^{5} / 100 \mu \mathrm{L} /\right.$ well $)$. Phytohemagglutinin (PHA) (Sigma) was used at concentration of $5 \mu \mathrm{g} / \mathrm{mL}$. The studied compound was used at concentrations of 1, 10 and $100 \mu \mathrm{g} / \mathrm{mL}$. As a control, appropriate dilution of DMSO in the culture medium was used. The cultures were incubated for $72 \mathrm{~h}$ in a cell culture incubator. The degree of cell proliferation was measured by a colorimetric method [12]. The results were presented as a mean OD value from quadruplicate wells $\pm \mathrm{SE}$.

\section{Determination of Cytokine Production in Whole Blood Cell Cultures}

Venous blood from a single donor was diluted fivefold with RPMI 1640 medium and placed in 24-well culture plates
(Nunc). Production of cytokines was induced by an addition of lipopolysaccharide (LPS) from E. coli, serotype 0111:34 (3 × 10 $0^{6}$ E.U. $\left.\mathrm{mg}^{-1}\right)($ Sigma) at a dose of $1 \mu \mathrm{g} /$ $\mathrm{mL}$. The studied compound (I) was added to the cultures at concentrations of 10 and $100 \mu \mathrm{g} / \mathrm{mL}$. As a control, appropriate dilutions of DMSO in the culture medium were used. After $24 \mathrm{~h}$ incubation in a cell culture incubator the supernatants were harvested and kept at $-20{ }^{\circ} \mathrm{C}$ until cytokine determination. The activities of tumor necrosis factor alpha (TNF- $\alpha$ ) and interleukin 6 (IL-6) were determined using bioassays [13, 14].

\section{Results and Discussion}

\section{Crystal Structure}

The title compound and its solvate crystallize in the orthorhombic noncentrosymmetric space groups $P c a 2_{1}$ (I) and $P 2{ }_{1} 2_{1} 2_{1}$ (II), respectively. There are two independent molecules (A and B) in the asymmetric unit of (I) (Fig. 1), whereas the asymmetric part of (II) consists of one molecule of 4H-1,2,4-triazole derivative and one DMSO solvent

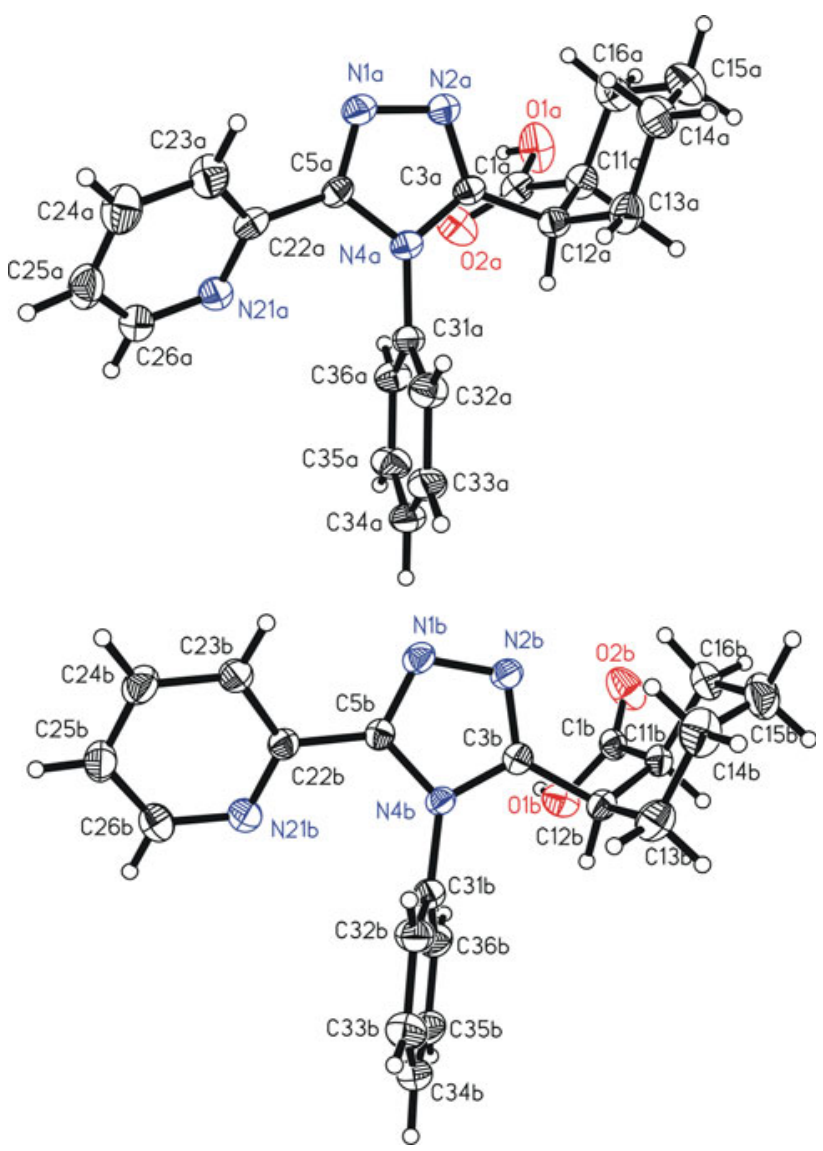

Fig. 1 The perspective view of molecules (I) with $30 \%$ probability displacement ellipsoids 
moiety (Fig. 2). Dimethyl sulfoxide in (II), as in many other crystalline solvates $[15,16]$, is partly disordered, with two positions occupied by the $\mathrm{S} 1$ atom and the H-atoms of methyl groups. The positions of $\mathrm{O} 1 \mathrm{~s}, \mathrm{C} 1 \mathrm{~s}$ and $\mathrm{C} 2 \mathrm{~s}$ atoms are not affected by the disorder. Moreover, complexation of (I) with DMSO induces enantiomeric self-resolution, forming homochiral domains (with enantiomer $11 S, 12 R$ or $11 R, 12 S)$ in twinned crystals [17]. It is an interesting example of spontaneous resolution of racemic compound by an achiral guest. A very similar behaviour was observed for 2,7-bis(trifluoromethyl)tricyclo[4.3.1.1 $\left.1^{3,8}\right]$-undecanesyn-2,syn-7-diol [18] and cyclo-bis(2-amino-7-cyano-4methoxyindan-2-carboxylic) acid [19]. It is very likely that the polarity of solvent influences the racemic resolution process which was observed in other cases [20, 21].

The central 1,2,4-triazole ring of (I) is substituted at the C3, N4 and C5 atoms by 2-cyclohexanecarboxylic acid, phenyl and 2-pyridyl groups, respectively. Bond lengths and angles within the triazole ring are not equal (Table 2) but comparable (within $3 \sigma$ ) in all three conformers and similar to those observed in related structures [22, 23]. A small difference in the geometry of triazole rings is observed only for N1-N2 bonds, which may result from different interaction patterns. The pyridyl and phenyl rings are twisted with respect to the 1,2,4-triazole plane; interplanar angles are 43.9 (3), $80.6(3)^{\circ}$ (molecule IA), 31.8 (3), $69.7(3)^{\circ}$ (molecule IB) and 24.0 (5) and $88.7(5)^{\circ}$ (II), respectively. The second conformational difference between the molecules (IA), (IB) and (II) is in the orientation of carboxyl group (Fig. 3). The relative orientation of the carboxyl O1(H) and chiral $\mathrm{C} 12$ atoms of the cyclohexane ring is described by the $\mathrm{O} 1-\mathrm{C} 1-\mathrm{C} 11-\mathrm{C} 12$ torsion angle (Table 2) indicating both trans or cis conformations. These differences depend on a pattern of intermolecular hydrogen bonds in which $\mathrm{O} 1$ atoms act as donors.

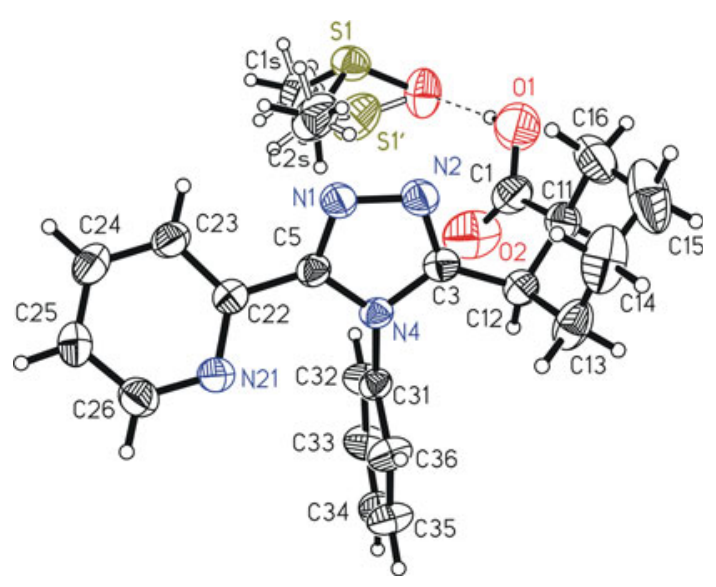

Fig. 2 The asymmetric unit of (II). Displacement ellipsoids are drawn at the $30 \%$ probability level. Dashed lines indicate hydrogen bonds
Table 2 Selected geometric parameters

\begin{tabular}{lllr}
\hline & \multicolumn{1}{l}{$(\mathbf{I})$} & \multicolumn{1}{l}{$(\mathbf{I I})$} \\
\cline { 2 - 3 } & $\mathrm{A}$ & $\mathrm{B}$ & \\
\hline Bond lengths $(\AA)$ & & & \\
N2-N1 & $1.394(4)$ & $1.385(4)$ & $1.372(5)$ \\
$\mathrm{N} 2-\mathrm{C} 3$ & $1.311(4)$ & $1.308(4)$ & $1.313(5)$ \\
$\mathrm{N} 4-\mathrm{C} 3$ & $1.363(4)$ & $1.371(4)$ & $1.385(5)$ \\
$\mathrm{C} 5-\mathrm{N} 4$ & $1.373(4)$ & $1.372(4)$ & $1.377(5)$ \\
$\mathrm{N} 1-\mathrm{C} 5$ & $1.307(4)$ & $1.313(4)$ & $1.304(5)$ \\
$\mathrm{C} 1-\mathrm{O} 1$ & $1.300(5)$ & $1.322(4)$ & $1.257(7)$ \\
$\mathrm{C} 1-\mathrm{O} 2$ & $1.203(5)$ & $1.197(4)$ & $1.189(8)$ \\
Torsion angles $\left({ }^{\circ}\right)$ & & & \\
N1-C5-C22-N21 & $137.0(4)$ & $147.0(4)$ & $-153.3(4)$ \\
C12-C11-C1-O1 & $171.9(4)$ & $-35.3(5)$ & $145.9(5)$ \\
\hline
\end{tabular}

The most characteristic feature of crystal (I) is the presence of two alternating ribbons (Fig. 4), build separately by the symmetry independent molecules. Each ribbon is linked by the $\mathrm{O} 1-\mathrm{H} 1 \cdots \mathrm{N} 1$ hydrogen-bonds (Table 3) in the $C(8)$ chain motif [24]. As shown in Fig. 4, molecules (IA) form a catemer around the two-fold screw axis, while the catemer of molecules (IB) runs about the $c$-glide plane. Thus, the first one is enantiopure and the second is racemic. Further, weak intermolecular $\mathrm{C}-\mathrm{H} \cdots \mathrm{N} /$ $\mathrm{O}$ hydrogen bonds link adjacent chains of the molecules (IA) and (IB).

As a result of the racemic resolution by solvent, in the crystal structure of (II) the host molecule, i.e. $4 H-1,2,4-$ triazole derivative, is one of enantiomers $(11 S, 12 R$ or $11 R, 12 S)$, depending on the part of twinned crystal. Two chemical components, host and guest, are linked by a very short and nearly linear $\mathrm{O} 1-\mathrm{H} 1 \cdots \mathrm{O} 1 \mathrm{~s}$ hydrogen bond (Table 3; Fig. 5). Moreover, the guest DMSO molecules in (II) play a vital role in the supramolecular aggregation participating, both as an acceptor and donor, in an extended net of weak $\mathrm{C}-\mathrm{H} \cdots \mathrm{O}$ and $\mathrm{C}-\mathrm{H} \cdots \mathrm{N}$ hydrogen bonds to host molecules (Fig. 5; Table 3).

\section{Biological Activity}

Compound (I) was tested for its potential activity to affect proliferative response of human peripheral blood mononuclear cells (PBMC) to phytohemagglutinin (PHA) and lipopolysaccharide (LPS)-induced tumor necrosis factor alpha (TNF- $\alpha$ ) and interleukin 6 (IL-6) production by human whole blood cell cultures. In addition, the effect of (I) on PBMC survival in $24 \mathrm{~h}$ culture at the concentration range of $5-100 \mu \mathrm{g} / \mathrm{mL}$ was tested.

The results showed that (I) caused about $40.5 \%$ inhibition of the proliferative response of PBMC to PHA at 


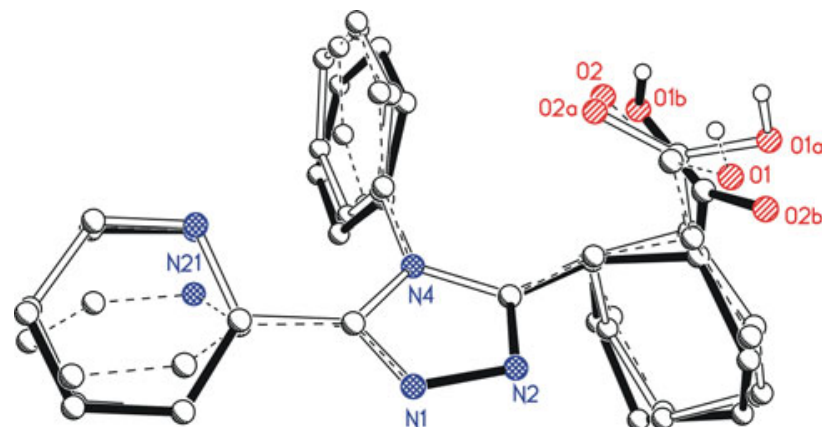

Fig. 3 The molecular fit through the triazole atoms of molecules (IA) (open lines), (IB) (full lines) and (II) (dashed lines)

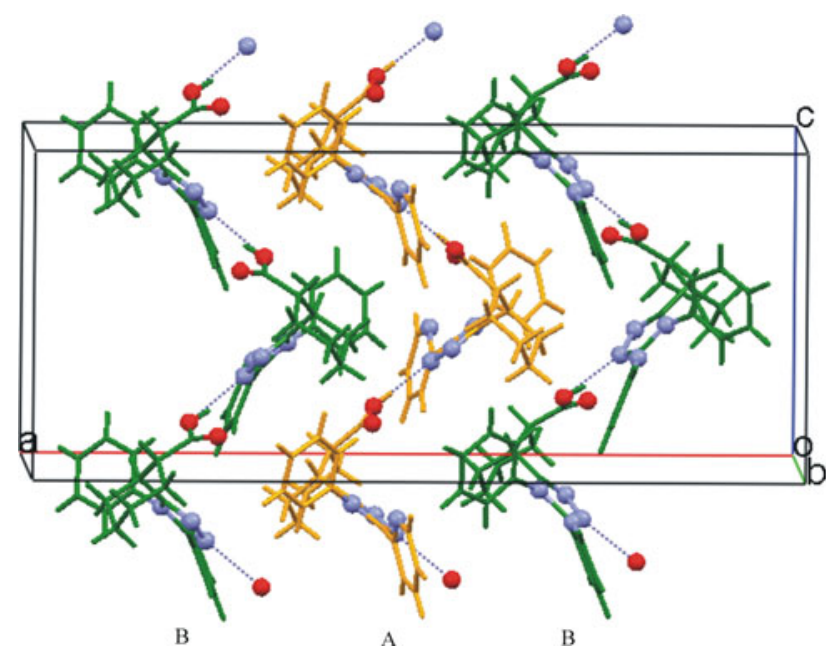

Fig. 4 The crystal structure of (I) viewed along the $b$ axis. The catemers of molecules (IA) and (IB) are marked. Dashed lines indicate hydrogen bonds

Table 3 Hydrogen-bonding geometry

$\begin{array}{llll}\begin{array}{l}\mathrm{D}-\mathrm{H} \\ (\AA)\end{array} & \begin{array}{l}\mathrm{H} \cdots \mathrm{A} \\ (\AA)\end{array} & \begin{array}{l}\mathrm{D} \cdots \mathrm{A} \\ (\AA)\end{array} & \begin{array}{l}\angle \mathrm{D}-\mathrm{H} \cdots \mathrm{A} \\ \left({ }^{\circ}\right)\end{array}\end{array}$

(I)

$\begin{array}{lllll}\mathrm{O}_{1 \mathrm{~A}}-\mathrm{H} 1 \mathrm{~A} \cdots \mathrm{N} 1 \mathrm{~A}^{(\mathrm{i})} & 0.82 & 1.92 & 2.688(5) & 157 \\ \mathrm{O}^{\mathrm{B}}-\mathrm{H} 1 \mathrm{~B} \cdots \mathrm{N}^{(\mathrm{ii})} & 0.82 & 1.90 & 2.706(5) & 167 \\ \mathrm{C} 25 \mathrm{~B}-\mathrm{H} 25 \mathrm{~B} \cdots \mathrm{O} 2 \mathrm{~B}^{(\mathrm{iii})} & 0.93 & 2.43 & 3.285(6) & 153 \\ \text { II) } & & & & \\ \mathrm{O} 1-\mathrm{H} 1 \cdots \mathrm{O} 1 \mathrm{~s} & 0.82 & 1.85 & 2.660(7) & 172 \\ \mathrm{C} 24-\mathrm{H} 24 \cdots \mathrm{O} 1 \mathrm{~s}^{\text {(iv) }} & 0.93 & 2.65 & 3.554(6) & 162 \\ \mathrm{C} 26-\mathrm{H} 26 \cdots \mathrm{O} 1 \mathrm{~s}^{\text {(v) }} & 0.93 & 2.71 & 3.536(6) & 150 \\ \mathrm{C} 13-\mathrm{H} 13 \mathrm{a} \cdots \mathrm{O} 1 \mathrm{~s}^{\text {(vi) }} & 0.97 & 2.67 & 3.540(7) & 150 \\ \mathrm{C} 1 \mathrm{~s}-\mathrm{H} 1 \mathrm{~S} 2 \cdots \mathrm{N} 1^{\text {(iv) }} & 0.96 & 2.49 & 3.357(7) & 151 \\ \mathrm{C} 2 \mathrm{~s}-\mathrm{H} 2 \mathrm{~S} 3 \cdots \mathrm{N} 2^{\text {(iv) }} & 0.96 & 2.63 & 3.415(7) & 139 \\ \mathrm{C} 33-\mathrm{H} 33 \cdots \mathrm{O} 1^{\text {(vii) }} & 0.93 & 2.54 & 3.368(7) & 148\end{array}$

Symmetry codes: (i) $1-x, 1-y, 1 / 2+z$; (ii) $1 / 2-x, y, 1 / 2+z$; (iii) $1 / 2-x, y+1, z-1 / 2$; (iv) $x-1 / 2,1 / 2-y,-z$; (v) $1 / 2-x$, $-y, z+1 / 2$; (vi) $x+1 / 2,-y-1 / 2,-z$; (vii) $x-1 / 2,-1 / 2-y,-z$

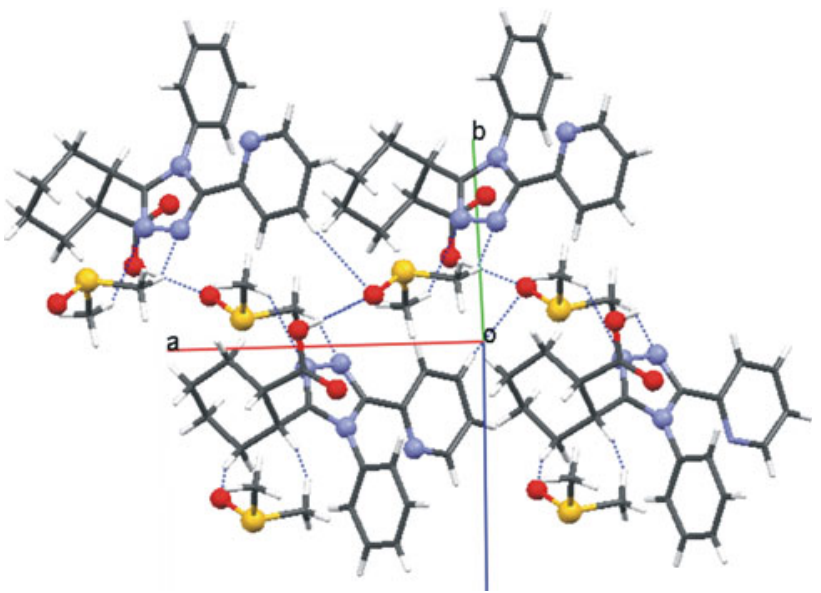

Fig. 5 The chain formed by the $\mathrm{O}-\mathrm{H} \cdots \mathrm{O}$ and $\mathrm{C}-\mathrm{H} \cdots \mathrm{O} / \mathrm{N}$ hydrogen bonds between host and guest molecules in (II). Dashed lines indicate hydrogen bonds

$100 \mu \mathrm{g} / \mathrm{mL}$ and a similar inhibition (43.3\%) of TNF- $\alpha$ production at $10 \mu \mathrm{g} / \mathrm{mL}$. IL-6 production was not affected. Importantly (I) was completely devoided of cell toxicity up to the concentration of $100 \mu \mathrm{g} / \mathrm{mL}$. Therefore, both the inhibition of cell proliferation and $\mathrm{TNF}-\alpha$ production could not be due to its toxicity. In conclusion, the preliminary results indicate a weak antiproliferative and a moderate antiinflammatory property of the compound.

\section{Supplementary Material}

CCDC-802411 and CCDC-802412 contains the supplementary crystallographic data for this paper. Copies of available materials can be obtained free of charge on application to CCDC, 12 Union Road, Cambridge CB2 1EZ, UK (fax: (+48) 1223-336-033; e-mail: data_request@ccdc.cam.ac.uk or http://www.ccdc.cam.ac.uk/data_request/cif).

Open Access This article is distributed under the terms of the Creative Commons Attribution Noncommercial License which permits any noncommercial use, distribution, and reproduction in any medium, provided the original author(s) and source are credited.

\section{References}

1. Matesanz AI, Pastor C, Souza P (2007) Inorg Chem Commun 10:97

2. Nath M, Sulaxna, Song X, Eng G (2006) J Organomet Chem 691:1649

3. Beckmann U, Brooker S (2003) Coord Chem Rev 245:17

4. Al-Masoudi IA, Al-Soud YA, Al-Salihi NJ, Al-Masoudi NA (2006) Chem Heterocycl Compd 42:1377

5. Holla BS, Rao BS, Sarojini BK, Akberali PM, Kumari NS (2006) Eur J Med Chem 41:657

6. Al-Soud YA, Al-Dweri MN, Al-Masoudi NA (2004) Farmaco 59:775 
7. Collin X, Sauleau A, Coulon J (2003) Bioorg Med Chem Lett 13:2601

8. Allen FH (2002) Acta Crystallogr B58:380

9. Kuma Diffraction (1998) KM-4 Software, version 10.3. Kuma Diffraction, Wroclaw

10. Sheldrick GM (2008) Acta Crystallogr A64:112

11. Flack HD, Bernardinelli G (2000) J Appl Crystallogr 33:1143

12. Hansen MB, Nielsen SE, Berg K (1989) J Immunol Methods 119:203

13. Espevik T, Nissen-Meyer J (1986) J Immunol Methods 95:99

14. Van Snick J, Vink A, Uyttenhove C, Coulie PG, Rubira MR, Simpson R (1986) J Proc Natl Acad Sci USA 83:9679

15. Harper JK, Dalley NK, Mulgrew AE, West FG, Grant DM (2001) Acta Crystallogr C57:64

16. Pedireddi VR, Belhekar D (2002) Tetrahedron 58:2937

17. Nguyen VT, Chan IYH, Bishop R, Craig DC, Scudder ML (2009) New J Chem 33:1736
18. Bishop R, Downing GA, Craig DC, Scudder ML (1998) J Incl Phenom Macrocycl Chem 31:145

19. Jagadish B, Carducci MD, Bosshard C, Gunter P, Margolis JI, Williams LJ, Mash E (2003) Cryst Growth Des 3:811

20. Sakai K, Sakurai R, Hirayama N (2004) Tetrahedron Asymmetry 15:1073

21. Gotrane DM, Deshmukh RD, Ranade PV, Sonawane SP, Bhawal BM, Gharpure MM, Gurjar MK (2010) Org Proc Res Dev 14:640

22. Mazur L, Koziol AE, Modzelewska-Banachiewicz B (2007) Acta Crystallogr E63:03455

23. Mazur L, Koziol AE, Modzelewska-Banachiewicz B (2008) Acta Crystallogr C64:0574

24. Bernstein J, Davis RE, Shimoni L, Chang NL (1995) Angew Chem Int Ed Engl 34:1555 